\title{
LAS UNIONES HOMOAFECTIVAS CELEBRADAS EN EL EXTRANJERO. SISTEMA VENEZOLANO DE DEREGHO INTERNACIONAL PRIVADO*
}

\author{
FOREIGN SAME SEX PARTNERSHIPS IN THE VENEZUELAN \\ STSTEM OF PRIVATE INTERNATIONAL LAW
}

\author{
Claudia Lugo HolmQUisT** \\ Mirian RODRÍGUEZ REYES***
}

RESUMEN: Una mirada a los sistemas jurídicos que han introducido regulaciones en materia de uniones afectivas entre personas del mismo sexo revela que cada vez son más los ordenamientos jurídicos estatales y los fallos jurisprudenciales que se suman al reconocimiento de tales uniones, o bien a reconocerles al menos los efectos de tipo personal, social y/o patrimonial que de ellas puedan desprenderse. En Venezuela, el panorama no evidencia esa tendencia, y apenas jurisprudencialmente ha habido tímidos avances. En este trabajo presentamos, en una primera parte, el estatus normativo y jurisprudencial que nos ofrece el
ABSTRACT: A preliminary look upon those legal systems which have introduced regulations on same sex partnerships, reveal that there is an increasing acceptance and recognition of the latter by statutes and/or case-law. In some instances, such recognition may encompass at least few personal, social, or in rem effects. In Venezuela, the legal landscape is quite opposed to such partnerships, although having experienced some timid judicial advancements on the matter. In this study, we firstly introduce the normative and case-law status offered by the Venezuelan system and how different essays directed at such recognition, proposed by various interest groups, including human rights organizations, have been torpedoed by the State through its different administrative

* Artículo recibido el 17 de julio de 2016 y aceptado para su publicación el 2 de diciembre de 2016.

** Abogada y tesista de la Maestría de Derecho Internacional Privado y Comparado de la Universidad Central de Venezuela (UCV). Profesora de pregrado de derecho internacional privado de la misma universidad y de la Universidad Metropolitana (UNIMET). Abogada en ejercicio.

*** Abogada por la Universidad Católica Andrés Bello. Magister Scientiarum en derecho internacional privado y comparado, doctora en ciencias mención derecho y profesora de posgrado en la Universidad Central de Venezuela (UCV). Profesora de pregrado de derecho internacional privado y secretaria general de la Universidad Metropolitana (UNIMET).

Boletín Mexicano de Derecho Comparado nueva serie, año XLX, núm. 149, mayo-agosto de 2017, pp. 777- 806

D. R. (C) 2017. UNAM, Instituto de Investigaciones Jurídicas. 
Esta revista forma parte del acervo de la Biblioteca Jurídica Virtual del Instituto de Investigaciones Jurídicas de la UNAM

sistema venezolano y cómo los intentos de salida o solución para el reconocimiento de las uniones homoafectivas que han propuesto por vías institucionales los grupos defensores de tales uniones, y en general, de los derechos humanos, han sido torpedeadas por el Estado a través de sus distintos órganos. En una segunda parte, exponemos las implicaciones del tema en dos aspectos del contenido del derecho internacional privado: la determinación del derecho aplicable y la eficacia extraterritorial de las sentencias extranjeras. Finalmente, haremos algunas consideraciones a ser tomadas en cuenta en la búsqueda de alternativas de solución que resultarían viables para la problemática planteada, partiendo del estatus normativo y jurisprudencial existente.

Palabras clave: uniones homoafectivas, derecho internacional privado, derecho extranjero, eficacia extraterritorial de sentencias extranjeras. organs. Secondly, we introduce the implications of such partnerships in two of the contents of Private International Law: the determination of the applicable law and the recognition of foreign judgments. Finally, we introduce some considerations directed at finding potential solutions to the challenges presented by such partnerships, based on current legislation and case-law.
Keyzeords: Same sex partnerships, private international law, foreign law, recognition of foreign judgments.

SUMARIO: I. Introducción. II. Estatus normativo y jurisprudencial de las uniones homoafectivas en Venezuela. III. Implicaciones en el derecho internacional privado. IV. Consideraciones para alternativas de solución. V. Conclusión. VI. Bibliografia.

\section{INTRODUCCIÓN}

Un ejercicio figurado de lo que simbolizaría el status normativo y jurisprudencial de las uniones homoafectivas u homoparentales en Venezuela, bien pudiera lograrse con la representación del laberinto de Creta de la mitología griega. La leyenda del laberinto en la isla de Creta, que albergaba al minotauro, y a quien periódicamente se le ofrendaban jóvenes en sacrificio, nos lleva a visualizar a donceles y doncellas venezolanos que luchan entre las enmarañadas rutas posibles por encontrar una salida para evitar ser 
Esta revista forma parte del acervo de la Biblioteca Jurídica Virtual del Instituto de Investigaciones Jurídicas de la UNAM

devorados por las fauces de un Estado y una sociedad que actúan como el propio monstruo mitológico.

Haciendo a un lado el análisis que pudiera enmarcarse en la acción de la sociedad - toda vez que éste más bien concerniría a un estudio sociológico, que aquí no pretendemos abordar - concentrémonos en el quehacer del Estado, al que, en todo caso, le correspondería asumir las acciones de tipo normativo y jurisprudencial en el marco de una política gubernamental orientada a dar soluciones a situaciones que son una realidad - más que global - y frente a la cual no tiene sentido ser indiferentes.

Hoy en día, el panorama comparado muestra que cada vez son más los ordenamientos jurídicos estatales y los fallos jurisprudenciales que se suman al reconocimiento de las uniones afectivas entre personas del mismo sexo, o bien a reconocerles al menos los efectos de tipo personal, social y/o patrimonial que de ellas puedan desprenderse.

Sin embargo, es sabido que en nuestro país la tendencia apunta en sentido contrario. La ausencia de legislación autónoma sobre la materia es la nota característica, y solamente la unión heterosexual bajo las formas del matrimonio y de las uniones estables de hecho sin impedimentos de ley, a lo sumo, el concubinato, ha merecido protección jurídica. En efecto, la unión configurada bajo tales formas es reconocida constitucional, legal y jurisprudencialmente sólo entre un hombre y una mujer; además, los efectos personales y patrimoniales previstos en nuestro ordenamiento que puedan derivarse de tales uniones son aplicables exclusivamente a estos tipos de alianzas. La imposición es aplicable a los supuestos de hecho internos o nacionales, vale decir, sin elementos de extranjería.

Una visión estrictamente positivista y restrictiva abogaría por considerar tal imposición igualmente aplicable, sin excepción alguna, a los supuestos con elementos de extranjería caracterizados por estar conectados a ordenamientos jurídicos extranjeros, a cuyo conocimiento y solución del derecho internacional privado le concerniría su atención y estudio. Pero el derecho internacional privado contemporáneo admite soluciones que no siempre son en blanco y negro.

Precisamente en este ámbito del derecho internacional privado pretendemos enfocar las posibles soluciones que nuestro sistema ofrecería a estas realidades. Los contactos que a diario los venezolanos hacemos con el mundo exterior y las relaciones que en razón de tales establecemos, nos hace partícipes del tráfico jurídico externo que configura el objeto de 
Esta revista forma parte del acervo de la Biblioteca Jurídica Virtual del Instituto de Investigaciones Jurídicas de la UNAM www.juridicas.unam.mx

DOI: http://dx.doi.org/10.22201/iij.24484873e.2017.149.11357

estudio de nuestra disciplina, y a la vez nos impone el deber de no mantenernos indiferentes. Ello supone que ya no resulta improbable que al operador jurídico venezolano se le presentaran con pasmosa frecuencia, casos referidos a uniones homoafectivas conectadas a ordenamientos jurídicos como España, Argentina, Uruguay, Chile, Ecuador, Colombia, México, Canadá, Estados Unidos de Norteamérica, ${ }^{1}$ Holanda, Bélgica, Francia, Irlanda, Islandia, Suecia o cualquiera de los tantos ordenamientos jurídicos que hoy son permisivos y protegen tales uniones, cualquiera que sea la fórmula jurídica que le hayan endilgado para reconocerlas, vale decir matrimonio, concubinato, unión civil, unión registral, etcétera.

En efecto, recientemente se dio a conocer el caso de Bárbara y Daniela, dos venezolanas que en junio de 2014 contrajeron matrimonio en Rosario, Argentina, y quienes enfrentan en Venezuela la falta de reconocimiento de su unión, muy a pesar de haberse dado bajo la legislación argentina, que la admite y protege. ${ }^{2}$ También vendría a colación el caso de Migdelis, cuya causa en la que reclamaba para sí y su hijo nacido en Argentina y concebido bajo la técnica de reproducción in vitro con óvulos de su pareja Giniveth, el reconocimiento de sus derechos hereditarios tras la muerte de ésta, con quien había contraído nupcias en ese país. ${ }^{3} \mathrm{Al}$ respecto, el 15 de diciembre de 2016, la Sala Constitucional ${ }^{4}$ reconoció $^{-}$ la doble filiación materna por participar ambas mujeres con material genético en el proceso de gestación por ovodonación, y en consecuencia, declaró el derecho del hijo a ser inscrito en el registro civil con los apellidos de ambas madres y a participar en los derechos sucesorales de la de cujus. Esta decisión constituye un paso al frente en la lucha de la defensa de estas parejas, si bien no se pronuncia sobre el matrimonio celebrado válidamente en Argentina, y los aspectos de derecho internacional privado contenidos en el fallo - particularmente en el Voto Salvado-,

1 Cualquiera que sea el estado de que se trate, a razón del criterio sentado por la sentencia Obergefell, la cual señaló que no existe una base legal para que un Estado en particular niegue el reconocimiento de un matrimonio entre personas del mismo sexo celebrado legalmente en otro de los Estados. Véase http://wrere.supremecourt.gov/ opinions/14pdf/14-556_3204.pdf

2 Consúltese Prensa Acvi del 1o. de julio de 2014, Venezuela.

3 Véase http://wrerr.ultimasnoticias.com.ve/noticias/actualidad/sucesos/mp-investiga-asesinato-de-la-sobrina-de-soto-rojas.aspx del 15 de diciembre de 2014, Venezuela.

4 TSJ/SC: núm. 1187, Migdelis Miranda Rondón, 15 de diciembre de 2017. 
Esta revista forma parte del acervo de la Biblioteca Jurídica Virtual del Instituto de Investigaciones Jurídicas de la UNAM

distan mucho de ser merecedora de elogios, por cuanto invoca sin mayor asidero tres instituciones, como lo son el orden público, el fraude a la ley y las situaciones jurídicamente creadas conforme a un derecho extranjero.

Como el caso de estas parejas, diversas son las situaciones que han podido válidamente ser constituidas fuera de nuestras fronteras bajo la vigencia de un derecho extranjero, y cuyos efectos pretendan hacerse valer en nuestro territorio, de paso, que no se limitarían a la unión homoafectiva propiamente dicha, sino que además pudieran ser derivadas de éstas, tales como la disolución del vínculo, el régimen patrimonial y el sucesoral, el cambio de sexo, de nombre y de estado civil y los subsiguientes cambios en el registro civil, la obligación de manutención, la inscripción del cónyuge en el seguro social, la solicitud conjunta de créditos para adquisición de viviendas, la adopción de menores realizada por parejas homoafectivas, etcétera.

Buscar soluciones jurídicas a esas situaciones que han nacido fuera de nuestras fronteras conforme a leyes extranjeras que sí las reconocen y les procuran protección jurídica, y que de alguna manera pretendan surtir efectos en Venezuela, puede resultar una tarea titánica bajo el actual estado normativo y jurisprudencial con que se cuenta. Sin embargo, queremos hacer hincapié en esa búsqueda. Esto, partiendo de salidas legales disponibles, posiblemente no sean las más idóneas, pero al fin y al cabo, puestas a disposición por nuestro sistema; eso sí, mientras el legislador venezolano no asuma su deber de legislar al respecto, lo cual sería lo deseable.

Veamos brevemente, en un primer plano, el estatus normativo y jurisprudencial que nos ofrece el sistema venezolano y cómo los intentos de salida o solución para el reconocimiento de las uniones homoafectivas que han propuesto por vías institucionales los grupos defensores de tales uniones, y en general, de los derechos humanos, han sido torpedeadas por el Estado a través de sus distintos órganos. En un segundo plano mostraremos las implicaciones del tema en dos aspectos del contenido del derecho internacional privado, y finalmente haremos algunas consideraciones para alternativas de solución a partir del estatus normativo y jurisprudencial existente, que resultarían viables para la problemática planteada. 
Esta revista forma parte del acervo de la Biblioteca Jurídica Virtual del Instituto de Investigaciones Jurídicas de la UNAM www.juridicas.unam.mx

DOI: http://dx.doi.org/10.22201/iij.24484873e.2017.149.11357

\section{ESTATUS NORMATIVO Y JURISPRUDENCIAL DE LAS UNIONES HOMOAFECTIVAS EN VENEZUELA}

\section{El estatus normativo}

El bloque normativo previsto en el título III, capítulo I (artículos 19 y ss.) de la Constitución de la República Bolivariana de Venezuela, ${ }^{5}$ contentivo de las disposiciones generales atinentes a los deberes, derechos humanos y garantías, en su conjunto proveen un marco constitucional idóneo para la defensa y protección no sólo de los derechos y garantías establecidos, sino además de los no expresamente anunciados; protección que se extiende a los instrumentos internacionales, como tratados, pactos y convenciones sobre derechos humanos que por aplicación del artículo 23 gozan de jerarquía constitucional y prevalecen en el orden interno. ${ }^{6}$ No obstante, carecemos de regulación autónoma y protección para las uniones homoafectivas, carencia que se extiende tanto a las fuentes internacionales como a las nacionales, para asuntos de derecho interno como para los casos que

5 Gaceta Oficial, 24 de marzo de 2000, enmendada el 15 de febrero de 2009, publicada en Gaceta Oficial, 19 de febrero de 2009.

6 En tal sentido, la Declaración Universal de los Derechos Humanos, suscrita por Venezuela mediante Resolución 217, del 10/12/48, Convención de las Naciones Unidas sobre el Consentimiento para el Matrimonio, la Edad Mínima para Contraer Matrimonio y el Registro de los Matrimonios (Gaceta Oficial, 31 de agosto de 1982), Declaración Americana de los Derechos y Deberes del Hombre (Bogotá, Colombia, mayo de 1948), Pacto Internacional de Derechos Económicos, Sociales y Culturales (Gaceta Oficial, 28 de enero de 1978), así como la Declaración sobre Orientación Sexual e Identidad de Género (presentada el 18 de diciembre de 2008 ante la Asamblea General de las Naciones Unidas), Observación General Número 20 de la ONU, 2009, sobre la no discriminación y los derechos económicos, sociales y culturales y resoluciones de la Asamblea General de la OEA (AG/RES. 2435 (XXXVIII-O/08), AG/RES. 2504 (XXXIX-O/09), AG/RES. 2600 (XL-O/10), AG/RES. 2653 (XLI-O/11), AG/RES. 2653 (XLI-O/11), AG/RES. 2807 (XLIII-O/13), AG/RES. 2863 (XLIV-O/14). Cabe destacar que el 26 de marzo de 2014 se publicó en la Gaceta Oficial del Estado Bolívar, núm. 1420, el Acuerdo 003-2014, mediante el cual se rechaza todo tipo de acto o manifestación discriminatoria o represiva que vulnere o menoscabe la personalidad e identidad de las personas sexo-diversas, en los diferentes municipios y comunidades en todo el territorio de dicho Estado, y se declaró el 17 de mayo de cada año como el día estadal de la "No discriminación y el respeto por la orientación sexual e identidad de género". 
Esta revista forma parte del acervo de la Biblioteca Jurídica Virtual del Instituto de Investigaciones Jurídicas de la UNAM

presentan elementos de extranjería y que interesan al derecho internacional privado. Por su parte, el artículo 77 constitucional protege a razón de nuestra jurisprudencia, como podremos constatar más adelante, solamente a las uniones heterosexuales bajo las formas del matrimonio y de uniones estables de hecho sin impedimentos de ley, y, al parecer, sólo el concubinato no tiene tales impedimentos.

La ausencia de regulación especial también se extiende a las uniones homoafectivas integradas por personas transgénero, término con el que se designa a las personas que se identifican sicológicamente o viven asumiendo un género opuesto a su sexo biológico, se haya o no sometido a tratamientos hormonales o cirugías de reasignación de sexo; ${ }^{7}$ y a pesar de la dilatada regulación garantista sobre derechos humanos, dentro de los cuales toma cuerpo la libertad a la diversidad de género, pareciera que la protección se circunscribe a la consideración de las personas transgénero como sujetos considerados aisladamente, es decir, no formando parte de posibles uniones afectivas. En tal sentido, se ha afirmado que uno de los dos problemas legales básicos que enfrentan estas personas puede ir, desde la prohibición de casarse con una persona de aparente sexo opuesto hasta permitirle el matrimonio o la unión con una persona del mismo sexo, pudiendo verse inmersas una vez que se han sometido a un proceso de reasignación de sexo, en situaciones de matrimonio heterosexual o en matrimonio homosexual según se reconozca en la legislación que se analice. ${ }^{8}$ Tomando en cuenta la delimitación de este trabajo, el supuesto de unión homoafectiva integrado por personas transgénero, aquí lo hemos asumido como una referencia al alcance de los problemas que pudieran presentarse, en tanto no pretendemos abordar la complejidad de los problemas relativos a la transexualidad. ${ }^{9}$

7 Méndez Salom, Elizabeth, "La identidad de género en el derecho venezolano y argentino. Análisis comparado", en Derecho familiar internacional. Metodología para su estudio. Homenaje a Haydée Barrios, Bogotá, junio de 2014, p. 524.

8 El otro problema es el relativo al cambio de identidad legal. Guerra Hernández, Víctor Hugo, "Matrimonios del mismo sexo en el derecho internacional privado. Algunas reflexiones sobre el tema transexual", en Derecho familiar internacional. Metodología para su estudio. Homenaje a Haydée Barrios, Bogotá, junio de 2014, pp. 513 y 514.

9 En todo caso, Méndez Salom ha concluido que el bloque constitucional venezolano garantiza la protección de los derechos fundamentales de las personas transgénero, al tiempo que exhorta a la adopción de políticas públicas dirigidas a combatir la discrimi- 
Esta revista forma parte del acervo de la Biblioteca Jurídica Virtual del Instituto de Investigaciones Jurídicas de la UNAM www.juridicas.unam.mx

DOI: http://dx.doi.org/10.22201/iij.24484873e.2017.149.11357

La desatención a las uniones homoafectivas por parte del codificador venezolano ha dado paso a un proyecto de ley sobre matrimonio igualitario (Proyecto de Ley de Matrimonio Civil Igualitario), introducido en la Asamblea Nacional en enero de 2014, y actualmente a la espera de su discusión. El mismo partió de la iniciativa de más de cuarenta agrupaciones no gubernamentales defensoras de los derechos de los homosexuales, bisexuales, lesbianas y transexuales; no obstante, salió al paso en julio de ese mismo año, la consignación de una propuesta ante el mismo ente por parte del partido político Nuvipa (Nueva Visión para mi País), a fin de que la Asamblea no legisle a favor del matrimonio igualitario. Se espera que este panorama cambie a raíz de la elección de Tamara Adrián, activista venezolana transgénero que se alzó con una diputación tras las elecciones parlamentarias celebradas el 6 de diciembre de 2015, y quien ha informado que impulsará leyes que garanticen los derechos de la comunidad LGBT (lesbianas, gays, bisexuales, transgéneros), entre las cuales está la Ley de Matrimonio Igualitario. ${ }^{10}$

A todo evento, convendría que el proyectista y el legislador venezolano tomaran en consideración la opinión del catedrático español, Álvarez González, quien en referencia a la Ley 13/2005 española, que introdujo la modificación al Código Civil y permitió el derecho a contraer matrimonio entre personas del mismo sexo, señaló la inconveniencia de legislar sin tomar en cuenta la dimensión internacional de los supuestos ${ }^{11}$ es decir, los casos con elementos de extranjería. Sobre el particular, destacó que ni el legislador francés con la introducción del Pacte civil de solidarité ni el legislador español, fueron capaces de prever la avalancha de casos que se presentarían, siendo que la lógica de establecer que "donde antes se leía matrimonio a partir de ahora se lee matrimonio entre personas de idéntico o distinto sexo", pasaba por alto una de las características más viejas de los matrimonios internacionales, como lo es "la posibilidad de aplicar un derecho extranjero a determinados aspectos directamente vinculados a la

nación basada en la orientación sexual e identidad de género. Méndez Salom, Elizabeth, op. cit., p. 535. Coincide en ello Guerra Hernández, Víctor Hugo, pp. 515 y 516.

10 Véase http://wrere.el-nacional.com/politica/Tamara-AdrianLey-Matrimonio-igualitario-podria_0_753524804.html del 14 de diciembre de 2015, Venezuela.

11 Álvarez González, Santiago, "Dimensión internacional del matrimonio entre personas del mismo sexo: Lo que el ojo del legislador español no vio", en http://wrwreacademia. edu/4494589/Dimension_internacional_del_matrimonio_entre_personas_del_mismo_sexo. 
Esta revista forma parte del acervo de la Biblioteca Jurídica Virtual del Instituto de Investigaciones Jurídicas de la UNAM

celebración del matrimonio o para los que la existencia de un matrimonio es un prius", cuestión que en definitiva plantea la dificultad, entre otros aspectos, de aplicar a los matrimonios entre personas del mismo sexo una normativa concebida para matrimonios heterosexuales, y que el estatus matrimonial sea reconocido en el extranjero.

Lo que se extrae de observar el estatus normativo venezolano sobre la materia entraña un panorama nada alentador para las uniones homoafectivas, especialmente para los casos de derecho internacional privado.

\section{El estatus jurisprudencial}

Diversas sentencias se han pronunciado, entre otros aspectos, sobre el cambio de nombre y registro civil como efecto del cambio de sexo por "razones de incongruencia de género"; ${ }^{12}$ y en todas las cuales la consideración de la persona transgénero es la de una individualidad y no como integrante de una unión homoafectiva.

Por su parte, los fallos que han atendido solicitudes de reconocimiento o efectos jurídicos derivados de uniones entre personas del mismo sexo han sido desfavorables para los solicitantes, siendo una excepción el reciente fallo que reconoce la doble filiación materna en una unión homosexual, arriba reseñado y respecto al cual correspondería un desarrollo detallado

12 Véanse en Méndez Salom, Elizabeth, op. cit., nota 6, pp. 539-542, y en Domínguez Guillén, María Candelaria, "Algunas sentencias que declaran el cambio de sexo", RFCFP, Caracas, UCV, 2007, pp. 64-92. Además, consúltense Juzgado Primero de Primera Instancia en lo Civil, Mercantil, Tránsito y Trabajo de la Circunscripción Judicial del Estado Falcón, Tucacas, María Carolina Sguerzi Simonuti, 4 de julio de 2005; Juzgado Primero de Primera Instancia en lo Civil, Mercantil y del Tránsito de la Circunscripción Judicial del Estado Miranda, Candelaria Claret Urbina Páez, Expediente 23.659, 28 de octubre de 2005; Juzgado Primero de Primera Instancia en lo Civil, Mercantil y del Tránsito del Segundo Circuito de la Circunscripción Judicial del Estado Portuguesa, M. D. V.J. A., 18 de enero de 2007; Juzgado del Municipio Diego Ibarra de la Circunscripción Judicial del Estado Carabobo, Georgina Alexandra Hernández Bravo, Expediente 1188-08, 26 de junio de 2009; Juzgado Primero de Primera Instancia en lo Civil, Mercantil y del Tránsito de la Circunscripción Judicial del Estado Zulia, Luis Harvey Patiño Moreno, Expediente 44.484, 30 de abril de 2010. Es declarada inadmisible por presentar los originales de los informes médicos; Juzgado Superior Primero en lo Civil, Mercantil y del Tránsito de la Circunscripción Judicial del Estado Zulia, Luis Harvey Patiño Moreno, 28 de julio de 2011 . Apelación de la sentencia anterior, declarada sin lugar y confirma la sentencia del tribunal a quo. 
Esta revista forma parte del acervo de la Biblioteca Jurídica Virtual del Instituto de Investigaciones Jurídicas de la UNAM

en otro trabajo. Menos reciente, una sentencia de un tribunal municipal ${ }^{13}$ negó la solicitud de registro como unión estable de hecho, de la unión establecida por 16 años entre dos venezolanos, cuyo petitorio se basó en que en el articulado de la Ley Orgánica de Registro Civil (artículos 117 cardinal 3,119,121) tal registro no se encuentra entre las prohibiciones expresamente enunciadas en la ley, y que los artículos 151 y 152 proporcionan al juzgador "un rango de apreciación más amplio que la simple interpretación literal de la Ley, cuando se trata de dilucidar situaciones oscuras, en cuya interpretación ha de prevalecer, como ya se indicara, el principio de favorabilidad de los derechos Humanos". La negativa responde a un criterio jurisprudencial asentado, y en esto nos enfocaremos a lo largo de este trabajo, producto de un fallo de la Sala Constitucional que ha sido determinante en la consideración de este tipo de uniones, erigido sobre la base de que la unión de hecho estable protegida por el artículo 77 constitucional ha de ser entendida sólo entre un hombre y una mujer. En este nos detendremos de seguidas, en vista al impacto que produce en la materia que nos ocupa.

El criterio reiterado de la Sala Constitucional del Tribunal Supremo de Justicia en razón del cual el principio constitucional de igualdad ante la ley y a la no discriminación impone la obligación estatal de dar trato igual a quienes se encuentren en un plano de igualdad y desigual a quienes estén en desiguales condiciones, ${ }^{14}$ envuelve una predisposición hacia el no reconocimiento de los efectos jurídicos emanados de las uniones homoafectivas. En ese sentido, el más representativo de los fallos de la Sala Constitucional, como lo es el dictado en 2008 con ocasión a la solicitud de interpretación de los artículos 21, cardinal 1, y 77, en conjunción con los artículos 19, 20 y 22 de la Constitución, ${ }^{15}$ caso Unión Afirmativa de Venezuela, constituye uno de los obstáculos más determinantes que ha enfrentado la lucha por el reconocimiento de esa causa.

13 Juzgado Primero de Municipio de la Circunscripción Judicial del Área Metropolitana de Caracas, José Ramón Merentes Correa y Giovanni Roberto Tarullo di Giacomo, 31 de octubre de 2013.

14 TSJ/SC: núm. 536, Michelle Brionne Gandon, 8 de junio de 2000; núm. 1197, Luis Alberto Peña, 17 de octubre de 2000; núm. 3242, Ramón Rovero Zambrano, 18 de noviembre de 2003; núm. 190, Asociación Civil Afirmativa de Venezuela, 28 de febrero de 2008; sobre esta última, haremos nuestros comentarios infra.

15 Realizada por la Asociación Civil Unión Afirmativa de Venezuela y otros. Véanse datos de sentencia en nota al pie núm. 12. 
Esta revista forma parte del acervo de la Biblioteca Jurídica Virtual del Instituto de Investigaciones Jurídicas de la UNAM

Para los casos con elementos de extranjería que a futuro pudieran presentársele al operador jurídico venezolano, el contenido de dicho fallo, por una parte, representa un impedimento para aplicar a las uniones homoafectivas por vía de la analogía las disposiciones que el sistema venezolano de derecho internacional privado prevé para el matrimonio, sus requisitos, efectos personales y patrimoniales y disolución; pero, por otra, deja abierta una salida hacia el reconocimiento de situaciones relativas a uniones homoafectivas constituidas válidamente conforme a legislaciones extranjeras. Sin entrar de lleno en el análisis del fallo, veamos los aspectos en favor y en contra que trae consigo para la solución de los casos que interesan al derecho internacional privado.

Independientemente del principal vacío que dejó la sentencia, el cual fue, como bien quedó sentado en el voto salvado que la acompañó, el haber "invisibilizado el problema de la intolerancia, del menosprecio o tratamiento degradante; y en general, de la exclusión social que afrontan las personas homosexuales o de identidad de género diversa; no por falta de reconocimiento de los derechos fundamentales, sino por la falta de garantías a todos y cada uno de esos derechos", vemos que el fallo se explaya en el argumento principal, que se circunscribe a que no existen condiciones de igualdad; por tanto, no pueden equipararse las uniones de personas del mismo sexo frente a aquellas como el matrimonio entre un hombre y una mujer y las uniones de hecho "que le son iguales, esto es, entre un hombre y una mujer". El argumento del fallo, pese a detenerse poco en exponer los criterios razonables que soportan el argumento de considerarlas uniones distintas - con lo cual se interpretaría que la convivencia, la estabilidad afectiva, el socorro mutuo, la solidaridad, los intereses en común, el deseo de constituir una familia, ${ }^{16}$ etcétera, parecieran ser atributos monopólicamente atribuidos a las uniones heterosexuales, y que no constituyen

16 En cuanto al deseo de constituir una familia, es sabido que el matrimonio, si bien contempla entre sus propósitos la procreación de descendencia, el mismo admite formas artificiales de procurársela, tales como la inseminación artificial y la adopción, entre otras, sin que por ello se desvirtúe la institución matrimonial, dado que el deseo de conformar familia no es el único objetivo perseguido por esta institución ni es exclusivo de ella. En el caso de las uniones homoafectivas, también aplicarían a nuestro parecer los mismos criterios de razonamiento, de manera que en el seno de estas últimas, ya por imposición de la naturaleza biológica de las partes, el medio de procurase la familia sería necesariamente artificial. 
Esta revista forma parte del acervo de la Biblioteca Jurídica Virtual del Instituto de Investigaciones Jurídicas de la UNAM

criterios razonables para establecer parámetros de equiparación o igualdad-, por lógica jurídica derivó en concluir que no existe trato discriminatorio al proveer un trato diferencial para ambos tipos de uniones. Tal trato diferencial, a criterio de la Sala, viene dado por la "protección reforzada" que establece la Constitución sólo para las uniones matrimoniales y estables de hecho monogámicas y heterosexuales, proveyendo en todo caso una "discriminación positiva" para estos tipos de alianzas.

En vista a su apego a la interpretación "literal y teleológica" de la Constitución, el fallo da por sentado la inutilidad de la analogía como fuente de derecho y, por tanto como útil herramienta de la hermenéutica jurídica, pues la no equiparación entre ambos tipos de uniones - heterosexuales y homosexuales - descarta la posibilidad de aplicar analógicamente la protección que la Constitución dio al matrimonio, así como al concubinato al equiparlo con aquél, a las uniones estables homosexuales.

\section{IMPLICACIONES EN EL DERECHO INTERNACIONAL PRIVADO}

Para los supuestos con elementos de extranjería que nos ocupan, lo anterior trae consigo implicaciones que afectan la resolución de los casos. A continuación distingamos esas implicaciones en dos de los aspectos que configuran el contenido del derecho internacional privado, a saber: en la determinación del derecho aplicable y en la eficacia extraterritorial de sentencias extranjeras.

\section{Implicaciones en el ámbito de la determinación del derecho aplicable}

Para los casos que interesan al derecho internacional privado en los cuales el juez venezolano deba resolverlos una vez que se haya definido y determinado su jurisdicción, observamos que la interpretación literal que dio el fallo de la Sala Constitucional afecta el aspecto de esta disciplina jurídica que conocemos como determinación del derecho aplicable al supuesto de hecho internacionalizado, lo cual se erige en uno de los aspectos negativos que comporta dicho fallo. En particular, en lo relativo a la calificación jurídica de la unión homoafectiva creada válidamente bajo un ordenamiento jurídico extranjero. 
Esta revista forma parte del acervo de la Biblioteca Jurídica Virtual del Instituto de Investigaciones Jurídicas de la UNAM

\section{A. La calificación}

La calificación en el derecho internacional privado ha sido considerada como una de sus instituciones más difíciles de abordar y regular, dada la autonomía que tiene el legislador de cada país a dar el nombre y contenido a sus instituciones de acuerdo con sus propias políticas y realidades. Los "conflictos de leyes" derivados de la diversidad de los derechos internos de cada país dan paso a lo que en los inicios de su aparición como problema de derecho internacional privado, el jurista alemán Franz Kahn llamó "conflictos latentes", ${ }^{17}$ posteriormente llamados por el francés Eugene Bartin como "conflictos de calificaciones". ${ }^{18}$ Según Maekelt, "La calificación se aplica — de allí su importancia - tanto en relación a la hipótesis de hecho, sobre la que se basa el caso iusprivatista internacional, como con respecto al factor de conexión de la norma de derecho internacional privado y su consecuencia jurídica". ${ }^{19}$ De manera que la cuestión de calificar constituye un prius para la determinación del derecho aplicable, en tanto que para poder distinguir la norma que determinará el ordenamiento jurídico que resolverá el caso con elementos de extranjería, es necesario previamente definir; es decir, calificar la situación de hecho planteada al juez. ${ }^{20}$

Es sabido que los ordenamientos jurídicos que han legislado en la materia para reconocer y proteger las uniones entre personas del mismo sexo han diferido en la calificación jurídica bajo la cual han instituido el reconocimiento. Así, algunos ordenamientos han preservado la institución matrimonial sólo para las uniones heterosexuales, llamando matrimonio únicamente a estas uniones (Venezuela); otros han dado una calificación extensiva a tal institución, incluyendo en la misma tanto a las uniones

17 Rouvier, Juan María, Derecho internacional privado. Parte general, 5a. ed., t. I, Maracaibo, 2006, p. 433.

18 Maekelt, Tatiana B., Teoría general del derecho internacional privado, 2a. ed., Caracas, Academia de Ciencias Políticas y Sociales, 2010, p. 322.

19 Maekelt, Tatiana B., Normas generales de derecho internacional privado en América, UCV, Caracas, FGJP, 1984, p. 88.

20 En este caso hemos decidido prescindir de la calificación del factor de conexión de la norma de conflicto, no por ser improbable la necesidad de calificarlo, toda vez que es posible que requiera hacerse, sino por no ser el propósito de este análisis, de manera que nos limitaremos a la calificación del supuesto de hecho de la norma, que en todo caso sería la relación jurídica internacionalizada relativa a uniones homoafectivas. 
Esta revista forma parte del acervo de la Biblioteca Jurídica Virtual del Instituto de Investigaciones Jurídicas de la UNAM www.juridicas.unam.mx

DOI: http://dx.doi.org/10.22201/iij.24484873e.2017.149.11357

heterosexuales como a las homosexuales (Holanda), mientras que otros le han dado calificaciones específicas a estas últimas uniones a fin de diferenciarlas del matrimonio, tales como uniones civiles (Argentina), relaciones registradas (Dinamarca, Holanda), relaciones de vida registradas (Alemania), cohabitación legal (Bélgica), concubinatos o uniones concubinarias (Uruguay), pactos civiles de solidaridad o pactos de asociación civil (Francia). ${ }^{21}$

El asunto es que el tratamiento diferencial que estableció el criterio de la Sala Constitucional conlleva a proscribir, para nosotros, la calificación jurídica "matrimonio" para las uniones entre personas del mismo sexo. Se desatan así una serie de efectos que forman una cadena o sucesión de obstáculos para la solución de los casos, y en concreto, para la determinación del ordenamiento jurídico que se aplicará al caso. Siguiendo el orden de prelación de las fuentes contenido en el artículo 1 de la Ley de Derecho Internacional Privado, ${ }^{22}$ tal cadena se presenta así: 1) no existe regulación autónoma sobre la materia en los tratados ratificados por Venezuela; 2) tampoco en las normas nacionales de derecho internacional privado (entre las cuales se contaría la Ley de Derecho Internacional Privado); 3) dada la anulación de la analogía como posible fuente de derecho que se interpretaría a razón del fallo de la Sala Constitucional, se daría por sentada la inaplicación de las normas relativas al matrimonio contenidas en las fuentes venezolanas — según podremos ver de seguido - ; finalmente, la invocación de los principios de derecho internacional privado generalmente aceptados nada parecen aportar a la causa si consideramos, por ejemplo, la interpretación jurisprudencial que sobre el principio de igualdad ante la ley y a la no discriminación ha dado la Sala Constitucional.

De manera que la determinación del derecho aplicable, por ejemplo, para comprobar a) la capacidad para celebrar "matrimonio" entre personas del mismo sexo, b) los requisitos de fondo para celebrarlo, c) los efec-

21 Sobre el alcance y contenido de estas figuras, véase Fresnedo de Aguirre, Cecilia, "Uniones matrimoniales y no matrimoniales. Su continuidad jurídica a través de las fronteras", Boletín Mexicano de Derecho Comparado, número conmemorativo, sexagésimo aniversario, México, 2008, pp. 321-327.

22 Gaceta Oficial, 6 de agosto de 1998. Dicho orden da prioridad a las normas de derecho internacional público establecidas en los tratados vigentes en Venezuela, en defecto de las cuales se acude a las previstas en las leyes, a falta de ellas, se acude a la analogía, y finalmente, a los principios de derecho internacional privado generalmente aceptados. 
Esta revista forma parte del acervo de la Biblioteca Jurídica Virtual del Instituto de Investigaciones Jurídicas de la UNAM

tos personales y patrimoniales que se derivan del mismo o d) el divorcio y la separación de cuerpos, no es posible realizarla en vista a la falta de regulación autónoma, y por tanto, de la "protección reforzada" que dio el constituyente en exclusividad a la institución matrimonial, así como al concubinato por equiparación al matrimonio.

Esto se traduce, en concreto, en que no puede ser utilizado el articulado previsto en nuestras fuentes de origen internacional que prevén la materia referida al matrimonio y al divorcio, que en nuestro caso sería únicamente el Código Bustamante ${ }^{23}$ - el cual sería aplicable en principio a supuestos de hecho vinculados con ordenamientos jurídicos de Estados contratantes de dicho tratado ${ }^{24}$ que regula lo atinente a las condiciones jurídicas que han de preceder a la celebración del matrimonio (artículos 36 al 38 y 40), a la forma del matrimonio (artículos 41 y 42), a los efectos del matrimonio en cuanto a las personas de los cónyuges (artículos 45 y 46), a la nulidad del matrimonio y sus efectos (artículos 47, 48 y 51), a la separación de cuerpos y divorcio (artículos 52 al 56), a los efectos patrimoniales del matrimonio (artículos 187 al 193), entre otros aspectos relacionados. Lo propio también ocurriría con las disposiciones de fuente nacional, como la Ley de Derecho Internacional Privado, en particular las referidas a los requisitos para contraer matrimonio (artículo 21), a los efectos personales y patrimoniales del matrimonio (artículo 22), al divorcio y a la separación de cuerpos (artículo 23), así como las relativas a otros supuestos que podrían derivarse del matrimonio, tales como las relaciones paternofiliales (artículo 24), la adopción (artículo 25), la tutela y demás instituciones de protección de incapaces (artículo 26), todas las cuales presumiblemente se circunscribirían a las uniones heterosexuales, dado que ni el Código Bustamante ni la Ley de Derecho Internacional Privado establecen regulación autónoma para las uniones entre personas

23 Suscrito en La Habana, Cuba, en 1928 y ratificado por Venezuela, ley aprobatoria promulgada el 23 de diciembre de 1931, depósito del instrumento de ratificación el 12 de marzo de 1931 y publicado en G. O., 9 de abril de 1932 .

24 El Código Bustamante se encuentra vigente frente a Cuba, Guatemala, Honduras, Nicaragua, Panamá, Perú, Haití, República Dominicana y Brasil. Hasta el presente, ninguno de estos países permite el matrimonio entre personas del mismo sexo, con lo cual no sería aplicable concretamente por esa razón. Pero si llegara a ser reconocido a futuro por alguno de tales países, y se presentara un caso vinculado al mismo ante los tribunales venezolanos, las disposiciones de dicho tratado referidas a la materia dejarían de ser aplicadas, pese a corresponder su aplicación, sólo por la interpretación jurisprudencial aludida. 
Esta revista forma parte del acervo de la Biblioteca Jurídica Virtual del Instituto de Investigaciones Jurídicas de la UNAM

del mismo sexo. Esto, como se expuso más arriba, en lo que respecta a la determinación del derecho aplicable al caso con elementos de extranjería que pudiera presentársele al juez venezolano.

Frente a esta consideración de no poder aplicar el articulado previsto en nuestras fuentes de origen internacional y nacional para determinar el derecho aplicable a los distintos supuestos arriba señalados, nos preguntamos entonces ¿esto hubiera variado si la aplicación analógica del articulado referido hubiera sido procedente? Pensamos que la respuesta es negativa para los casos en que las personas tuvieran domicilio en Venezuela (para el supuesto de determinar su capacidad para contraer matrimonio, vía artículo 21 de la Ley de Derecho Internacional Privado) o hubieran establecido domicilio común en Venezuela o éste sería su último domicilio en caso de tener domicilios distintos (para los efectos personales y patrimoniales, artículo 22 ejusdem), o si el domicilio del cónyuge que intenta la demanda se ubica en nuestro país (para el divorcio y la separación de cuerpos, artículo 23 ejusdem), o bien si el domicilio del hijo, del adoptante, del adoptado o del incapaz se encuentra en Venezuela (para los supuestos relativos a relaciones paternofiliales, adopción, tutela e instituciones de protección, artículos 24, 25 y 26 ejusdem, respectivamente). ¿Por qué? Porque los factores de conexión de las normas de conflicto venezolanas que regulan tales supuestos ordenan aplicar el derecho correspondiente al domicilio de las personas involucradas; y siendo éste el venezolano, la salida estuviera completamente cerrada: sólo reciben protección jurídica reforzada las uniones heterosexuales conformadas en los términos constitucionales ya conocidos.

Pero la respuesta sería un rotundo "sí", y, por tanto, sí hubiera variado la solución del caso si tales domicilios estuvieran establecidos en un país cuyo ordenamiento jurídico permitiera la unión homoafectiva en cualquiera de sus formas, sea matrimonio, concubinato, unión civil, unión registrada, pacto civil de solidaridad, etcétera, pues, resultaría aplicable el derecho extranjero permisivo, y eso al menos hubiera hecho una diferencia al representar una luz indicando una salida del laberinto.

\section{B. El orden público internacional}

La aplicación de un derecho extranjero permisivo a partir del factor de conexión domicilio indicado por la norma de conflicto venezolana también pudiera representar para cualquier escéptico - como lo sería el 
Esta revista forma parte del acervo de la Biblioteca Jurídica Virtual del Instituto de Investigaciones Jurídicas de la UNAM

magistrado disidente de la sentencia que declara el reconocimiento de la doble filiación, quien apela sin mayor explicación por la figura del orden público en el derecho internacional privado para justificar su posturala posibilidad de argumentar la evicción de la aplicación de tal derecho a razón del funcionamiento de la institución del orden público internacional. Pero precisamente, uno de los aspectos positivos que dejó sentado la sentencia del caso Unión Afirmativa de Venezuela fue la de que la Constitución no niega derechos a la unión entre personas del mismo sexo, con lo cual este tipo de unión sería violatoria del orden público interno; y nosotros agregamos: ni mucho menos del orden público internacional, cuestión en la que nos detendremos en el acápite destinado al ámbito de la eficacia extraterritorial de las sentencias extranjeras, en donde encontramos un panorama, más bien favorable a la causa.

No obstante, para los escépticos que aún sostendrían que la unión homosexual es violatoria del orden público interno, en razón del artículo 77 constitucional y 44 del Código Civil, la figura del orden público atenuado resultaría una válvula de escape, de carácter temporal mientras no exista regulación autónoma, pero solución al fin. El orden público internacional de efecto atenuado o parcial no se encuentra regulado expresamente en nuestro sistema de derecho internacional privado; sin embargo, recibe amplia aceptación por parte de la doctrina patria y reconocida además por la jurisprudencia venezolana. ${ }^{25}$ Esta figura, variante del orden público internacional, dado que se utiliza en el marco del funcionamiento de éste, atenúa los efectos dañinos que la aplicación del derecho extranjero o el reconocimiento de la sentencia extranjera podrían producir en el foro. Por ello su fin es el de "moldear la justicia del caso". ${ }^{26}$

Tiene su origen en Francia, y su utilización parte de una distinción entre las situaciones jurídicas que pretendan crearse en el foro y las situaciones jurídicas válidamente creadas en el extranjero, ${ }^{27}$ a las que nos referiremos de seguidas.

25 En tal sentido, puede verse Maekelt, Tatiana B., op. cit., pp. 365 y 366 . El efecto atenuado del orden público internacional es también invocado por Guerra Hernández como solución para los casos que nos ocupan. Véase al respecto, Guerra Hernández, Víctor Hugo, op. cit., pp. 487 y 488.

26 Silva, Jorge Alberto, Notas sobre..., op. cit., p. 59.

27 Consúltese Carrascosa González, Javier y Calvo Caravaca, Alfonso-Luis, Derecho internacional privado, 12a. ed., vol. I, Granada, 2011-2012, pp. 444-446. 
Esta revista forma parte del acervo de la Biblioteca Jurídica Virtual del Instituto de Investigaciones Jurídicas de la UNAM

$a$. Situaciones jurídicas que pretendan crearse en el foro

Las situaciones jurídicas que pretendieran "crearse" en el foro venezolano de conformidad con un derecho extranjero serían rechazadas por vulnerar los principios esenciales del orden público interno. Esto, aun cuando el derecho correspondiente al domicilio de uno o ambos contrayentes admitiera un concepto de matrimonio distinto al nuestro, en cuyo caso funcionaría la cláusula de orden público internacional prevista en el artículo 8 de la Ley de Derecho Internacional Privado; ${ }^{28}$ por ejemplo, al intentar constituir en Venezuela un "matrimonio" entre personas del mismo sexo de acuerdo con la ley española que es permisiva al respecto, sería inmediatamente rechazado, puesto que el orden público internacional funciona en estos casos, "de modo total, completo y radical". ${ }^{29}$

\section{b. Situaciones jurídicas válidamente creadas en el extranjero}

Si se tratara de situaciones jurídicas ya "creadas" en el extranjero con arreglo a un ordenamiento jurídico que las permite, por tanto, que ya han surtido sus efectos esenciales en el país extranjero, podrán desplegar su eficacia en el territorio nacional, específicamente los efectos "periféricos" y no "nucleares" derivados de ellas, por cuanto el contacto en el tiempo y en el espacio de tales situaciones con el foro es lejano y débil; en consecuencia, "no producen daño sustancial a la estructura básica y a la cohesión" 30 del Estado receptor. Esto se traduce, para el orden público internacional atenuado, por una parte, en que podría rechazarse la figura que entraría en pugna con el orden público venezolano, pero, por otra parte, se permitiría que sus efectos periféricos surtieran su eficacia en el territorio nacional. Por ejemplo, no se reconocería la figura propiamente dicha de la unión entre personas del mismo sexo conformada con arreglo a la ley extranjera; es decir, el efecto nuclear de la unión que sería la alianza aisladamente considerada y configurada bajo la forma legal en que se

28 Barrios, Haydée, "Requisitos para contraer matrimonio (artículo 21)", en Ley de Derecho Internacional Privado comentada, tomo I, Caracas, UCV/FGJP/CDCH, 2005, pp. 525 y 526 .

29 Carrascosa González y Calvo Caravaca, op. cit., p. 444.

30 Ibidem, p. 445. 
Esta revista forma parte del acervo de la Biblioteca Jurídica Virtual del Instituto de Investigaciones Jurídicas de la UNAM

constituyó (matrimonio, unión civil, pacto civil, relación registrada, etcétera). Pero los efectos derivados de ella, como podrían ser los de carácter patrimonial (por ejemplo, derecho a la repartición equitativa del patrimonio de la unión, a la obligación de manutención, etcétera), sucesoral (derecho a la vocación hereditaria), civil (derecho al patronímico o apellido derivado de la unión, al registro civil de dicho nombre, a la disolución del vínculo, etcétera) y/o social (derecho a la inscripción en el seguro social), serían respetados permitiéndoles desplegar plena eficacia en Venezuela.

Lo propio correspondería para la adopción de menores celebradas válidamente de acuerdo con un derecho extranjero. Así, se rechazaría la figura de la adopción propiamente dicha, por vulnerar la norma de la Ley Orgánica para la Protección de Niños, Niñas y Adolescentes ${ }^{31}$ contenida en el artículo 411, según el cual la adopción conjunta "sólo puede ser solicitada por cónyuges no separados o separadas legalmente, y por parejas conformadas por un hombre y una mujer, que mantengan una unión estable de hecho que cumpla los requisitos establecidos en la Ley"; pero se respetarían los derechos de los padres adoptivos y, especialmente, los derechos de los menores adoptados, quienes serían destinatarios de todos los atributos que conforman el contenido y extensión de tales derechos establecidos en su favor (responsabilidad de crianza, obligación de manutención, convivencia familiar, etcétera).

\section{Las normas de aplicación necesaria}

Por otra parte, se tiene la consideración del artículo 44 del Código Civil, ${ }^{32}$ coherente con el artículo 77 constitucional, en virtud del cual sólo se reconoce el matrimonio contraído entre un solo hombre y una sola mujer, artículo tradicionalmente tomado por la doctrina iusprivatista como una norma de aplicación inmediata o necesaria; ${ }^{33}$ es decir, una norma cuya aplicación, dada su naturaleza imperativa, provoca la desatención de todo elemento de extranjería que pudiera presentar el caso de derecho internacional privado, desaplicando de manera apriorística cualquier

31 Gaceta Oficial, 10 de diciembre de 2007.

32 Gaceta Oficial, 26 de julio de 1982.

33 Véase al respecto Barrios, Haydée, "Las reglas de derecho limitantes de su propio dominio de aplicación", Ponencias venezolanas al XI Congreso Internacional de Derecho Comparado, Caracas, FGJP, UCV, 1982, p. 100. 
Esta revista forma parte del acervo de la Biblioteca Jurídica Virtual del Instituto de Investigaciones Jurídicas de la UNAM www.juridicas.unam.mx

norma de conflicto e imponiendo como consecuencia la aplicación del derecho venezolano, inclusive por encima de tratados internacionales. Ahora bien, mientras exista el criterio jurisprudencial de no equiparación-no analogía y reconocido el apego de la Sala a la interpretación "literal" de las normas, el artículo 44 sería aplicable sólo a las uniones consideradas como "matrimonios", y, en todo caso, en virtud al precepto constitucional, a los concubinatos. Es decir, a favor de la causa, la razón que produce la exclusión de la analogía para incorporar las uniones estables de hecho entre personas del mismo sexo dentro de la calificación "matrimonio" también sería la misma razón para exceptuar tales uniones del supuesto de hecho del artículo 44. Pero esta alternativa de solución no nos satisface, porque representa una respuesta basada en una interpretación "literal" a un criterio jurisprudencial que hizo gala de esa técnica.

A todo evento, recomendaríamos para toda propuesta, llámese proyecto de ley, alegato, argumentación, etcétera, no calificar o denominar como "matrimonio" o "concubinato" a las uniones estables de hecho entre personas del mismo sexo. Tal aseveración podría plantear un debate sobre discriminación, cuestión que no esperaríamos sucediera, pero sería una recomendación preventiva ante los ya expuestos argumentos.

\section{El fraude a la ley}

Un obstáculo a superar a raíz del criterio jurisprudencial de la Sala Constitucional sería la referencia que en el fallo se hace al fraude a la ley. De acuerdo con los términos expresados en el fallo, el mismo estaría limitado al ámbito del disfrute de los derechos especialmente económicos; es decir, al respeto del establecimiento de una comunidad ordinaria de bienes, "siempre que no haya fraude a la ley" (véase supra). Si bien estimamos que el fraude mencionado en el fallo se refiere al reconocido en el derecho internacional privado, no hay duda que puede ser argüido por quienes no estarían proclives a reconocer ciertos derechos a las parejas homosexuales derivados de actos celebrados válidamente conforme a la legislación extranjera, como en efecto se pudo constatar en el voto salvado de la sentencia que declara la doble filiación de Migdelis y Giniveth respecto al hijo de ambas, al señalar el disidente que se había configurado un fraude a la ley venezolana al colocarse éstas bajo el imperio de la ley argentina. 
Esta revista forma parte del acervo de la Biblioteca Jurídica Virtual del Instituto de Investigaciones Jurídicas de la UNAM

Ante esto, es justo salir al paso con que en nuestras fuentes el fraude a la ley en el derecho internacional privado sólo está establecido como cláusula general en la Convención Interamericana sobre Normas Generales de Derecho Internacional Privado ${ }^{34}$ (artículo 6); por tanto, aplicable sólo a supuestos conectados a países que la ratificaron, como sería, por ejemplo, Argentina. Sin embargo, también sería justo señalar que la Ley de Derecho Internacional Privado no lo previó como cláusula general, y sólo contempla un supuesto para evitarlo, exclusiva y excepcionalmente limitado al ámbito de la determinación del derecho al divorcio y a la separación de cuerpos, situaciones éstas que están regidas por el derecho del domicilio del cónyuge demandante (artículo 23, primera parte). El legislador, para prevenir el fraude a la ley, exige un lapso de al menos un año para que surta efecto el cambio del domicilio del cónyuge demandante (artículo 23, segunda parte). El silencio del legislador nacional en cuanto al fraude a la ley, según Maekelt, se fundamentó en tres factores: la dificultad de probar la intención fraudulenta, la posibilidad de combatir el fraude con otra institución, como el orden público internacional concebido como excepción, y el deseo de disminuir las excepciones a la aplicación del derecho extranjero. ${ }^{35}$ Es sabido que el fraude a la ley en el derecho internacional privado implica la modificación fáctica del factor de conexión que establece la norma de conflicto del foro, a fin de evitar la aplicación del derecho normalmente aplicable. Pero justamente, la dificultad de probar la intención fraudulenta de violar la legislación normalmente aplicable deja prácticamente al fraude a la ley desprovisto de suficiente asidero para justificarlo, pues no está prohibido que las personas cambien en los hechos; por ejemplo, su domicilio.

Tampoco sería posible invocar la disposición contenida en la citada Convención aludiendo ser un principio de derecho internacional privado generalmente reconocido, precisamente porque el silencio de la ley, buena parte como producto de la ausencia de consenso para consagrarlo, presume que la figura está muy lejos de ser considerada un principio general.

En todo caso, la función que cumpliría el fraude a la ley estaría, tal como señala Maekelt, involucrada dentro del propósito que cumple el orden público internacional, y respecto al cual fijaremos posición partiendo del criterio jurisprudencial de la Sala Constitucional.

\footnotetext{
34 Gaceta Oficial, Montevideo, 26 de junio de 1985, CIDIP II, 1979.

35 Maekelt, Tatiana B., op. cit., p. 373.
} 
Esta revista forma parte del acervo de la Biblioteca Jurídica Virtual del Instituto de Investigaciones Jurídicas de la UNAM www.juridicas.unam.mx

DOI: http://dx.doi.org/10.22201/iij.24484873e.2017.149.11357

\section{Implicaciones en el ámbito de la eficacia extraterritorial de las sentencias extranjeras}

La sentencia extranjera, como mandato del juez que acogió o rechazó la pretensión hecha valer en la demanda que le dio origen al juicio extranjero, puede contener pronunciamientos que configuran situaciones jurídicas válidamente creadas de acuerdo con el ordenamiento jurídico aplicado por dicho juez. El alcance extraterritorial de estas situaciones da pie al reconocimiento o rechazo que exprese el Estado receptor, a través de sus propios mecanismos y condiciones para que en él puedan desplegarse tales efectos. Así, el rechazo de una sentencia extranjera cuyo reconocimiento se pretende, busca evitar que las situaciones jurídicas contenidas en la parte dispositiva de la misma puedan surtir efectos en Venezuela, por ser incompatibles con los principios fundamentales del ordenamiento jurídico venezolano. ${ }^{36}$

En el marco de la eficacia extraterritorial de sentencias, en particular, de aquellas emanadas de autoridades extranjeras cuya parte dispositiva verse sobre la constitución, disolución, efectos personales o patrimoniales, sucesión, etcétera, de una unión entre personas del mismo sexo establecida conforme a una legislación extranjera, y cuyo propósito sería el de surtir efectos en Venezuela, lo conducente, de acuerdo con el procedimiento de exequátur previsto en nuestras fuentes, a saber: la Convención Interamericana sobre Eficacia Extraterritorial de las Sentencias y Laudos Arbitrales Extranjeros ${ }^{37}$ y la Ley de Derecho Internacional Privado, sería verificar la conformidad de todos los requisitos previstos en tales fuentes a fin de darle el respectivo pase, total o parcial, a dichas sentencias. De todos los requisitos, el que principalmente plantearía dificultades prácticas a los fines de la eficacia de las referidas sentencias sería el del orden público internacional.

36 Pérez Pacheco, Yaritza, La sentencia extranjera en Venezuela. Requisitos-procedimiento-efectos, serie trabajos de Ascenso núm. 17, Caracas, UCV/FGJP, 2011 , p. 163.

37 Gaceta Oficial, 15 de enero de 1985. En materia de eficacia extraterritorial de sentencias extranjeras, la Convención se convierte en la práctica, en la única fuente internacional aplicable, en tanto el Acuerdo sobre Ejecución de Actos Extranjeros o Acuerdo Boliviano de 1911, si bien vigente, lo está frente a Bolivia, Colombia, Ecuador y Perú, países en los cuales también se encuentra vigente la referida Convención, por lo que, tratándose de tratados sucesivos sobre la misma materia, prevalece el posterior. En cuanto al Código Bustamante, Venezuela reservó el capítulo referido a la ejecución de sentencias. 
Esta revista forma parte del acervo de la Biblioteca Jurídica Virtual del Instituto de Investigaciones Jurídicas de la UNAM

\section{A. El orden público internacional}

Respecto a tal requisito, entre las dos fuentes vigentes referidas arriba, se advierte una "discordancia", que actualmente se limita a tener carácter meramente formal, toda vez que en la práctica es más bien una concordancia. El orden público internacional, previsto expresamente como requisito en el literal "h" del artículo 2o. de la Convención, no está contemplado en la Ley como presupuesto de eficacia de sentencias extranjeras; sin embargo, la aparente discordancia ha sido salvada por la jurisprudencia patria al consolidar tal requisito exigiéndolo reiteradamente. ${ }^{38}$

Nuestro planteamiento consiste en que, ante situaciones jurídicas que previeran un estatus jurídico referido a la constitución, disolución, efectos personales o patrimoniales, sucesión, etcétera, de uniones entre personas del mismo sexo válidamente creadas conforme a una legislación extranjera, no pudiera invocarse el orden público internacional como presupuesto de eficacia de las sentencias extranjeras que establecieran, constituyeran, declararan o reconocieran tal estatus. El punto de partida de las luces que se vislumbran en el laberinto lo constituye el pronunciamiento que hace el fallo del caso Unión Afirmativa de Venezuela al no considerar reñidas con el orden público las uniones entre personas del mismo sexo. En efecto, el citado fallo señala:

...la norma constitucional no prohíbe ni condena las uniones de hecho entre personas del mismo sexo, que encuentran cobertura constitucional en el derecho fundamental al libre desenvolvimiento de la personalidad; simplemente no les otorga protección reforzada... De hecho, el disfrute de los derechos sociales y, especialmente, de los económicos, es perfectamente posible en el caso de uniones entre personas del mismo sexo, no a través de la comunidad concubinaria, lo cual no se generaría porque aquéllas no cumplen con los requisitos para ello, pero sí a través de una comunidad ordinaria de bienes, en los términos en que la legislación civil lo permite, siempre que no haya fraude a la ley y dentro de los límites que impone el orden público (por ejemplo, que no se burle con la comunidad ordinaria entre una persona casada y otra distinta de su cónyuge, la comunidad de gananciales entre esposos)... Así, salvo los límites que se expresaron que imponen el orden público y la

38 Sobre detalles de cómo ha funcionado y a través de cuáles mecanismos, véase Pérez Pacheco, Yaritza, op. cit., pp. 155-162. 
Esta revista forma parte del acervo de la Biblioteca Jurídica Virtual del Instituto de Investigaciones Jurídicas de la UNAM

prohibición de fraude a la ley, nada obsta para la admisión de la existencia, entre dos personas del mismo o de distinto sexo, de una comunidad ordinaria o una sociedad cuya causa sea el aporte común de bienes o esfuerzos, que está dirigida al logro de un fin, también común...

Estando las uniones homoafectivas permitidas por la Constitución y las leyes, siendo que lo que no tienen es una protección específica o "reforzada" y por tanto no pugnan con orden público venezolano, todo esto nos lleva a entender que mucho menos son manifiestamente contrarias al orden público internacional. Sí serían violatorias, tal como se desprende del fallo transcrito, si en la unión homoafectiva o la situación jurídica de que se trate, uno o ambos integrantes estuvieran casados individualmente; es decir, si se tratara de uniones adulterinas, con lo cual estarían violando en todo caso la comunidad de gananciales con sus respectivos cónyuges.

Ahora bien, precisamente la consideración que hace la Sala respecto al orden público recibió una severa crítica en el voto salvado de la magistrada disidente, quien señaló lo siguiente:

...También resulta impropio, en opinión de quien disiente, que para reconocer los efectos de las uniones de personas de un mismo sexo se remita - como lo hace la sentencia - al régimen jurídico de la sociedad civil o de la comunidad «...en los términos en que la legislación civil lo permite, siempre que no haya fraude a la ley y dentro de los límites que impone el orden público...», pues estos regímenes no parten de la institución social familiar. También en este punto lamentablemente, la mayoría sentenciadora desconoce la tendencia actual de la legislación comparada, pues numerosos países tienen tipificados en sus ordenamientos acuerdos legales que benefician a las parejas homosexuales con grados de compromisos y derechos diversos...

Nosotros entendemos que tanto la sentencia como el voto salvado no se refieren al orden público internacional, sino simplemente al interno, aunque el voto salvado pareciera confundir esta institución con un "orden internacional" al hacer referencia a la legislación comparada. De allí que sea impropio hablar de un "orden público internacional", como en efecto la doctrina iusprivatista ha insistido en aclarar, ${ }^{39}$ sino más bien de un

39 En tal sentido, véase Parra Aranguren, Gonzalo, Curso general de derecho internacional privado. Problemas selectos y otros estudios, 3a. ed., Caracas, UCV/FCJP, 1998, pp. 129 y 130. 
Esta revista forma parte del acervo de la Biblioteca Jurídica Virtual del Instituto de Investigaciones Jurídicas de la UNAM

"orden público en el derecho internacional privado", aunque resulte más fácil la expresión "orden público internacional".

Gualquiera que sea la forma como se le llame, orden público en el derecho internacional privado u orden público internacional, en el ámbito de la determinación del derecho aplicable, es entendido como una excepción a la aplicación del derecho extranjero declarado aplicable por la norma de conflicto del foro; mientras que en sede de exequátur es entendido igualmente como una excepción, pero a la eficacia de sentencias extranjeras. En ambas situaciones, es decir, tratándose de elegir el derecho aplicable o de determinar la eficacia de una sentencia extranjera, el elemento de extranjería que pretende "permearse" con sus efectos en el territorio nacional sería rechazado por representar una violación manifiesta a los principios esenciales del orden público interno.

$\mathrm{Al}$ respecto, cabe destacar que el orden público internacional, tal como señala Carrascosa, lo integran "principios", ${ }^{40}$ pero sólo los "fundamentales", entendidos como esenciales, básicos, imprescindibles o inherentes ${ }^{41}{ }^{4}$ los cuales "son siempre, por definición directrices generales"; por ejemplo, la no discriminación por raza o sexo, la igualdad de los cónyuges ante la ley, la monogamia matrimonial, etcétera, con lo cual resulta inexacto aludirse a normas de orden público, y en su lugar debe hacerse referencia a normas que contienen principios integrantes del orden público internacional. ${ }^{42}$

Lo importante de todo esto es que las uniones homoafectivas no violan los principios esenciales del orden interno venezolano; en consecuencia, no pudieran violar el orden público internacional, y sólo las situaciones jurídicas válidamente creadas conformes a una legislación extranjera que burlaran la comunidad ordinaria entre esposos, por estar casado individualmente uno - $\mathrm{O}$ ambos - integrantes de la unión homoafectiva, serían violatorias al orden público interno; por tanto, motivo para rechazar el pase de las mismas: una salida del laberinto.

40 Carrascosa González y Calvo Caravaca, op. cit., p. 440.

41 Silva, Jorge Alberto, "Notas sobre la vulneración del orden público internacional en el derecho internacional privado", Revista Mexicana de Derecho Internacional Privado y Comparado, núm. 25, Academia Mexicana de Derecho Internacional Privado y Comparado, México, 2009, pp. 51-54.

42 Carrascosa González y Calvo Caravaca, op. cit., pp. 440 y 441. 
Esta revista forma parte del acervo de la Biblioteca Jurídica Virtual del Instituto de Investigaciones Jurídicas de la UNAM

\section{B. Las situaciones jurídicas válidamente creadas conforme a un derecho extranjero}

La institución del reconocimiento de las situaciones jurídicas válidamente creadas ha sido concebida como una excepción al obstáculo que puede representar la actuación de la norma de conflicto del juez, justamente, por la posibilidad de que su aplicación desconozca los derechos subjetivos que se han formado al amparo de un ordenamiento jurídico extranjero. ${ }^{43}$

Prevista a través de diversas fórmulas tanto en nuestras fuentes convencionales (artículos 8o. del Código Bustamante y 7o. de la Convención Interamericana sobre Normas Generales de Derecho Internacional Privado) como nacionales (artículo 5o. de la Ley de Derecho Internacional Privado) de derecho internacional privado ${ }^{44}$ todas sus formulaciones coinciden en establecer entre los límites al reconocimiento de las situaciones jurídicas válidamente celebradas de conformidad con un derecho extranjero, la figura del orden público internacional, entendido en el alcance conceptual que modernamente se le endilga a esta figura, tal como hemos referido anteriormente. Aun cuando en sede de exequátur, la doctrina venezolana se ha pronunciado a favor de utilizar de manera autónoma la figura de las situaciones jurídicas válidamente creadas con base en el artículo 5o. de la Ley de Derecho Internacional Privado, para impedir el reconocimiento de sentencias extranjeras sin hacer consideraciones de orden público sustantivo (artículo 8o. ejusdem), a fin de evitar que puedan surtir efectos en Venezuela relaciones jurídicas incompatibles con los principios fundamentales del ordenamiento jurídico venezolano. ${ }^{45}$

43 Madrid Martínez, Claudia, "La continuidad de las relaciones jurídicas familiares en el espacio. La respuesta del derecho internacional privado venezolano", en Derecho familiar internacional. Metodología para su estudio. Homenaje a Haydée Barrios, Bogotá, junio de 2014, pp. 1075 y 1076.

44 Sobre detalles de su formulación, origen, diferencias de regulación y aplicación de la institución de las situaciones jurídicas válidamente creadas, véase Madrid Martínez, Claudia, op. cit., pp. 1071-1118.

45 Pérez Pacheco, Yaritza, op. cit., p. 165. Con este propósito aludido por Pérez Pacheco, suponemos que fue utilizada esta figura legal en el voto salvado de la sentencia que reconoce la doble filiación materna, si bien no estuvo respaldada por ningún argumento que sostuviera su procedencia. 
Esta revista forma parte del acervo de la Biblioteca Jurídica Virtual del Instituto de Investigaciones Jurídicas de la UNAM www.juridicas.unam.mx

DOI: http://dx.doi.org/10.22201/iij.24484873e.2017.149.11357

Ahora bien, libradas las uniones homoafectivas de un carácter contrario al orden público, aquellas celebradas válidamente según un derecho extranjero "producirán efectos en la República" en los términos previstos en la regulación.

\section{CONSIDERAGIONES PARA ALTERnATIVAS DE SOLUGiÓN}

Cualquier solución en el marco actual del estatus normativo y jurisprudencial venezolano que proporcione luces de salida en el laberinto debe partir de la consideración de no estar las uniones homoafectivas - no adulterinas - reñidas con el orden público venezolano, aprovechando uno de los aspectos positivos del fallo Unión Afirmativa de Venezuela.

Como consecuencia de ello, en el ámbito de la eficacia de las sentencias extranjeras, específicamente en las que se ve reflejado algún aspecto sobre constitución, disolución, efectos personales, patrimoniales o sucesorales, etcétera, de uniones homoafectivas establecidas válidamente conforme a las leyes de otros países que las respaldan y protegen, se vislumbra una salida, visto que tales sentencias no pueden ser rechazadas bajo las figuras excepcionales del orden público internacional y de las situaciones jurídicas válidamente celebradas conforme a un derecho extranjero.

Igualmente, en el ámbito de la determinación del derecho aplicable, la liberación del yugo del orden público de las uniones homosexuales da pie a respetar y aplicar el derecho extranjero permisivo que resultara aplicable en razón de la norma de conflicto que contiene el factor de conexión domicilio.

Como un prius para la determinación de ese derecho extranjero, merece subrayar el impacto negativo, según pudimos observar, derivado del criterio jurisprudencial de no equiparar las uniones homosexuales con las heterosexuales, que deja desguarnecida a las primeras de la "protección reforzada" prevista en la Constitución, de lo cual se desprende como corolario la proscripción de la calificación jurídica "matrimonio" para las uniones homosexuales y la consecuente imposibilidad de aplicar analógicamente las normas de fuente internacional y nacional contempladas para el matrimonio, el divorcio y otros supuestos legales ya abordados. Ante ello, hubiera sido lo deseable que no se desdeñara una herramienta valiosísima que proveen el derecho comparado y el derecho internacional privado contemporáneo para paliar los efectos provocados por los conflictos de ca- 
Esta revista forma parte del acervo de la Biblioteca Jurídica Virtual del Instituto de Investigaciones Jurídicas de la UNAM www.juridicas.unam.mx

DOI: http://dx.doi.org/10.22201/iij.24484873e.2017.149.11357

lificaciones existentes entre las instituciones de los ordenamientos jurídicos de las naciones, y que en lo sucesivo, mientras no exista legislación especial, pudiera servir para cambiar el criterio jurisprudencial de no equiparación.

Hoy en día, lo que se conoce como "calificación funcional", permite al operador jurídico indagar acerca del fin o la función social que cumplen las instituciones, con el propósito de establecer equivalencias o analogías entre ellas, y con ello evitar su desconocimiento fuera de las fronteras en que fueron concebidas. ${ }^{46}$ Ésta sería una importante vía para asimilar los efectos de una unión entre personas del mismo sexo celebrada válidamente fuera del territorio nacional conforme a un derecho extranjero a las instituciones matrimonial y concubinaria, pues se estaría tomando en cuenta, en términos de asimilación, el fin perseguido por estos tipos de uniones y no su configuración o conformación subjetiva; es decir, poco importa si la unión estuviera conformada por sujetos de distinto o igual sexo, sino más bien los fines perseguidos y los valores que los acompañan, como serían la procura de la estabilidad como pareja, el compañerismo, la solidaridad y el socorro mutuo, los intereses en común, la comunidad del patrimonio, el deseo de conformar una familia, etcétera.

\section{GONCLUSIÓN}

Estamos a favor de una legislación que proteja las uniones homoafectivas, esa sería la principal solución; pero reconocemos que en el estado actual de las cosas, esbozar consideraciones para alternativas de solución, y, más aún, proponer soluciones concretas, puede resultar un mero ejercicio mental y especulativo mientras no se materialicen políticas estatales dirigidas a salvar los obstáculos. Más allá del poco margen de acción que dejó la sentencia Unión Afirmativa de Venezuela, constituye una deuda pendiente del Estado venezolano el legislar sobre la materia, partiendo de que el artículo 77 constitucional, tal como en aquélla se admitió, no comporta "una prohibición, desconocimiento o condena de otras formas de uniones de hecho

46 La calificación funcional ha sido sugerida por nuestra doctrina para lograr los mismos efectos a que hemos aludido, pero en el ámbito de otra de las instituciones generales del derecho internacional privado, como lo es la institución desconocida. Véase al respecto Madrid Martínez, Claudia, "Instituciones generales de derecho internacional privado. Más allá del problema conflictual”, Estudios de derecho internacional privado. Homenaje a Tatiana Maekelt, Caracas, Edición UCAB, 2012, p. 174. 
Esta revista forma parte del acervo de la Biblioteca Jurídica Virtual del Instituto de Investigaciones Jurídicas de la UNAM

entre personas - de distinto o igual sexo - cuya regulación, en todo caso, corresponde al legislador". De darse tal legislación especial, paso seguido, habrá que reinterpretar el contenido del orden público venezolano, y con ello replantear los principios integrantes del orden público internacional, con lo cual se evidenciaría el carácter relativo de este último, cuya particularidad es la de variar en el tiempo y en el espacio. ${ }^{47}$

\section{BIBLIOGRAFÍA}

Álvarez GonzÁLEz, Santiago, Dimensión internacional del matrimonio entre personas del mismo sexo. Lo que el ojo del legislador español no vio.

BARrios, Haydée, "Las reglas de derecho limitantes de su propio dominio de aplicación", Ponencias venezolanas al XI Congreso Internacional de Derecho Comparado, Caracas, FGJP, UCV, 1982.

, "Requisitos para contraer matrimonio (artículo 21)", en Ley de Derecho Internacional Privado comentada, t. I, Caracas, UCV/FGJP/CDCH.

Garrascosa González, Javier y Calvo Caravaca, Alfonso-Luis, Derecho internacional privado, 12a. ed., vol. I, Granada, 2011-2012.

Domínguez Guillén, María Candelaria, "Algunas sentencias que declaran el cambio de sexo", RFCJP, Caracas, UCV, 2007.

ESCUDEY, Gaëtan, Le mariage homosexuel et le "nouvel ordre public international»: un surprenant changement de paradigme! a propos de l'arrêt de la cour d'appel de chambéry du 22 octobre 2013.

Fresnedo DE AGUIRRE, Cecilia, "Uniones matrimoniales y no matrimoniales. Su continuidad jurídica a través de las fronteras", Boletín Mexicano de Derecho Comparado, núm. conmemorativo, sexagésimo aniversario, México, 2008.

Guerra Hernández, Víctor Hugo, "Matrimonios del mismo sexo en el derecho internacional privado. Algunas reflexiones sobre el tema transexual", Derecho Familiar Internacional. Metodología para su estudio. Homenaje a Haydée Barrios, Bogotá, junio de 2014.

47 Un ejemplo sobre la variación del contenido del orden público internacional en materia de relaciones homoafectivas en el marco del ordenamiento jurídico francés puede verse en Escudey, Gaëtan, Le mariage homosexuel et le «nouvel ordre public international»: un surprenant changement de paradigme! a propos de l'arrêt de la cour d'appel de chambéry du 22 octobre 2013, en http://wwre.revuedlf.com/droit-international/le-mariage-homosexuel-et-le-nouvel-ordre-public-international-un-surprenant-changement-de-paradigme-commentaire. 
MADRID MARTíNEZ, Claudia, "La continuidad de las relaciones jurídicas familiares en el espacio. La respuesta del derecho internacional privado venezolano", Derecho familiar internacional. Metodología para su estudio. Homenaje a Haydée Barrios, Bogotá, junio de 2014.

, "Instituciones generales de derecho internacional privado. Más allá del problema conflictual", Estudios de derecho internacional privado, $\mathrm{Ho}_{0}$ menaje a Tatiana Maekelt, Caracas, Edición UCAB, 2012.

MéNDEZ SALOM, Elizabeth, "La identidad de género en el derecho venezolano y argentino. Análisis comparado", Derecho familiar internacional. Metodología para su estudio. Homenaje a Haydée Barrios, Bogotá, junio de 2014.

Maekelt, Tatiana B., Teoría general del derecho internacional privado, 2a. ed., Caracas, Academia de Ciencias Políticas y Sociales, 2010.

- Normas generales de derecho internacional privado en América, Caracas, UCV, FGJP, 1984.

PARRA Aranguren, Gonzalo, Curso general de derecho internacional privado. Problemas selectos y otros estudios, 3a. ed., Caracas, UCV/FGJP, 1998.

PÉREz PACheGo, Yaritza, La sentencia extranjera en Venezuela. Requisitos-procedimiento-efectos, Caracas, UCV/FGJP, 2011.

Rouvier, Juan María, Derecho internacional privado. Parte general, 5a. ed., t. I, Maracaibo, 2006.

SILVA, Jorge Alberto, "Notas sobre la vulneración del orden público internacional en el derecho internacional privado", Revista Mexicana de Derecho Internacional Privado y Comparado, México, 2009. 